\title{
DEVELOPMENT, CHARACTERIZATION AND SKIN IRRITATION OF MANGOSTEEN PEEL EXTRACT SOLID DISPERSION CONTAINING CLAY FACIAL MASK
}

\author{
SUCHIWA PAN-ONa,b, SORAVOOT RUJIVIPAT ${ }^{a}$, ANAN OUNAROONa, CHUENJID KONGKAEWa, WAREE \\ TIYABOONCHAI $\mathbf{a}^{\mathrm{a}, \mathrm{b}, \mathbf{c}^{*}}$
}

aFaculty of Pharmaceutical Sciences, Naresuan University, Phitsanulok 65000, Thailand, bThe Center of Excellence for Innovation in Chemistry (PERCH-CIC), Commission on Higher Education, Ministry of Education, Bangkok, Thailand, cThe Center of Excellence in Medical Biotechnology, Naresuan University, Phitsanulok 65000, Thailand

Email: wareet@nu.ac.th

Received: 03 Jul 2018, Revised and Accepted: 26 Jul 2018

\section{ABSTRACT}

Objective: To develop a clay facial mask containing mangosteen peel extract solid dispersion (MPESD) for enhancing $\alpha$-mangostin bioavailability and to determine suitable clay-based facial mask.

Methods: The MPESD were prepared by a melting-solvent method employing PVP K30 and poloxamer 188 as a carrier. The water solubility was determined by HPLC method. The in vitro skin permeability was examined using porcine ear epidermis. The effects of clay types on the physical stability of MPESD and $\alpha$-mangostin adsorption capacity were evaluated. The skin irritation was determined by $4 \mathrm{~h}$ human patch test.

Results: After dissolved optimal formulation of MPESD in water, the spherical micelle was observed with a mean size of $\sim 150 \mathrm{~nm}$ and showed significantly $\alpha$-mangostin water solubility enhancement of $\sim 7 \mathrm{mg} / \mathrm{ml}, 700$ times greater than MPE. Upon mixing the MPESD with clays, a dry powder was obtained. In vitro permeation studies of the MPESD mixed with titanium dioxide showed lowest $\alpha$-mangostin permeation, while MPESD mixed with mica or talcum showed similar permeation profile as free MPESD solutions. No sign of skin irritation was observed in volunteers after application of the MPESD-based clay facial mask patch on the inner forearm skin for $4 \mathrm{~h}$.

Conclusion: MPESD demonstrates a promising technique for improving water solubility and permeation of $\alpha$-mangostin which reducing the staining effect. In addition, it is safe for topical application and cosmetically acceptable.

Keywords: $\alpha$-mangostin, Clay, Facial mask, Permeation, Solid dispersion

(C) 2018 The Authors. Published by Innovare Academic Sciences Pvt Ltd. This is an open access article under the CC BY license (http://creativecommons.org/licenses/by/4.0/) DOI: http://dx.doi.org/10.22159/ijap.2018v10i5.28247

\section{INTRODUCTION}

Facial mask treatments are among the oldest cosmetic products that available in various types. The wash-off typing based on clay materials is one of the most popular face masks according to clay advantages including softness, small particle size, $\mathrm{pH}$ similar to that of the skin, astringent effect, good physical exfoliation, moisturizer and refreshing action. Moreover, clays readily take in impurities and sebum due to their structure and high adsorption capacity [1].

In the market, many clay facial masks are available, mostly in combination with herbs that could increase their efficacy. Mangosteen peel extract (MPE), isolated from the peel of Garcinia mangostana Linn, is one of the most famous herbs widely used in a facial mask. The peel of mangosteen contained a high amount of $\alpha-$ mangostin, as a major component with yellowish color $[2,3]$. Fascinatingly, $\alpha$-mangostin can prevent hydroxyl radical scavenging property at a significantly higher degree than vitamin E [4]. Furthermore, MPE has anti-bacterial activity against Propionibacterium acnes, which has been recognized as pus-forming bacteria triggering inflammation in acne [5]. However, the poor aqueous solubility and the staining effect of MPE are the main problem for facial mask development [6].

To overcome these limitations, solid dispersion (SD) has been proposed as a carrier system to increase the MPE aqueous solubility. SD is a solid dosage form whereby the active substance is dispersed in an inert carrier. The mechanisms of enhanced drug water solubility include; reduced the drug particle into molecular size, as well as the changeability from crystalline to amorphous form, improved wettability and enhanced porosity $[7,8]$. Consequently, this approach could increase the $\alpha$-mangostin permeation through the skin, while reduce the staining effect.

Although the SD could increase the $\alpha$-mangostin water solubility, the high adsorption capacity of clays may lead to poor bioavailability due to the $\alpha$-mangostin adsorption on the clays. Therefore, in this study, we were the first to develop MPESD-based clay facial mask with enhanced bioavailability and safety. The mangosteen peel extracts solid dispersion (MPESD) were prepared and characterized in terms of physicochemical properties and solubility. Then, to determine the best commercial clay types for preparing the MPESDbased facial mask powders, the effects of types of clay on physical stability of MPESD, and in vitro permeation through porcine ear epidermis were evaluated. In addition, skin irritation of the MPESDbased clay facial mask was investigated in healthy volunteers.

\section{MATERIALS AND METHODS}

\section{Materials}

Standard $\alpha$-mangostin was purchased from ChromaDex (Lot No. 00013095-122, Bangkok, Thailand). Mangosteen peel dried powder was provided by Tipco $^{\circledR}$ (Prachuap Khiri Khan, Thailand). Polyvinylpyrrolidone K30 (Kollidon ${ }^{\circledR 3}$ ) was purchased from Bang Trading 1992 Co. (Bangkok, Thailand). Poloxamer 188 (Kolliphor ${ }^{\circledR}$ P188) was purchased from BASF Ltd. (Ludwigshafen, Germany). Sodium lauryl sulfate (SLS) was purchased from Ajax Finechem (Australia). Clays including mica, silicon dioxide $\left(\mathrm{SiO}_{2}\right)$, talcum (Talc) and titanium dioxide $\left(\mathrm{TiO}_{2}\right)$ cosmetic grade, were purchased from TTK Science Co. (Phitsanulok, Thailand). All other chemicals and reagents were used of analytical grade.

\section{Methods}

Preparation of mangosteen peel extract (MPE) and $\alpha$-mangostin content analysis

Dried powder of mangosteen peel was macerated with methanol (ratio 1:5) for $12 \mathrm{~h}$ (2 times) at room temperature. The extract was filtered through Whatman filter paper No. 1 and concentrated under reducing pressure. The crude extract was dried using hot air oven at $50^{\circ} \mathrm{C}$ and ground to obtain MPE. The percentage of yield was 
calculated by the following equation 1. Quantification of $\alpha$ mangostin in MPE was determined with high-performance liquid chromatography (HPLC, Shimadzu, Kyoto, Japan), equipped with LC10ATvp pump, SPD-10A UV detector and a reversed phase Vertisep C18 column $(5 \mu \mathrm{m}, 4.6 \times 250 \mathrm{~mm})$. The mobile phase consisted of $0.2 \%$ orthophosphoric acid and acetonitrile $(10: 90, \mathrm{v} / \mathrm{v})$. The analysis was conducted at a flow rate of $1 \mathrm{ml} / \mathrm{min}$ with the UV detector set at $320 \mathrm{~nm}$. MPE was kept at $4{ }^{\circ} \mathrm{C}$ in a tight and light protected container until used.

$$
\% \text { yield }=\frac{\text { Dried crude extract }(\mathrm{g})}{\text { Dried powder of } \mathrm{MPE}(\mathrm{g})} \times 100
$$

\section{Preparation of mangosteen peel extract solid dispersion (MPESD)}

MPESD was prepared by the melting-solvent method with various mass ratios of MPE, PVP K30 and poloxamer 188; 1:2:0, 1:4:0, 1:2:0.25, 1:2:0.5, 1:2:0.75, 1:4:0.25, 1:4:0.5 and 1:4:0.75. Briefly, PVP $\mathrm{K} 30$ and poloxamer 188 were melted with the aid of DI water. Then, the MPE was dissolved in absolute ethanol before adding into the melted PVP K30 and poloxamer 188 with constant stirring in an ice bath for $5 \mathrm{~min}$. Then, to remove the solvent, the samples were put in hot air oven at $45^{\circ} \mathrm{C}$ for $12 \mathrm{~h}$. Finally, the dried MPESD were ground using mortar and pestle before being kept in a desiccator at $4^{\circ} \mathrm{C}$ for further studies. Mangosteen peel extracts physical mixture (MPEPM) was obtained by mixing MPE, PVP K30 and poloxamer 188 with mortar and pestle.

\section{Determination of drug recovery and drug loading}

Ten mg of the MPESD were accurately weighed and dissolved in 10 $\mathrm{ml}$ of methanol. A $200 \mu \mathrm{l}$ sample was then diluted with mobile phase to $1 \mathrm{ml}$. The $\alpha$-mangostin was analyzed by HPLC as mentioned above. The percentage of drug loading and drug recovery were calculated by the following equation 2 and 3 , respectively.

$$
\begin{aligned}
& \alpha \text {-mangostin loading }(\%)=\frac{\text { Amount of the } \alpha-\text { mangostin from MPESD }}{\text { Weight of the MPESD }} \times 100 \ldots . . . \\
& \alpha \text {-mangostin recovery }(\%)=\frac{\text { Amount of the } \alpha \text {-mangostin from MPESD }}{\text { Amount of } \alpha \text {-mangostin added }} \times 100 \ldots
\end{aligned}
$$

\section{Solubility study}

An excess amount of the MPESD was added into $1 \mathrm{ml}$ of DI water and stirred at $900 \mathrm{rpm}$ for $24 \mathrm{~h}$ at room temperature. Samples were then centrifuged at $18000 \mathrm{rpm}$ for $30 \mathrm{~min}$, and the supernatant was filtered through a $0.45 \mu \mathrm{m}$ nylon filter membrane. Then, the amount of $\alpha$-mangostin in the supernatant was determined by HPLC as described above. All measurements were performed in triplicate.

\section{Physico-chemical characterization of MPESD}

\section{Mean particle size (MS) and size distribution}

The mean particle size (MS) and polydispersity index (PI) were characterized by the dynamic light scattering (DLS) technique employing the ZetaPALS® analyzer (Brookhaven Instrument Corporation, Holtsville, USA). This instrument was equipped with a $35 \mathrm{~mW}$ heliumneon laser diode operating at $632.8 \mathrm{~nm}$ and a BI-200SM Goniometer connected to a BI-9010AT digital correlator. All samples were diluted with DI water. The MS and PI value were analyzed by auto measuring mode at a fixed angle of $90^{\circ}$ and run for 6 measurement cycles. The particle size data were analyzed using a hydrodynamic diameter and the measurement was performed in triplicate.

\section{Morphology}

Ten mg of the MPESD was dissolved in $1 \mathrm{ml}$ of the DI water. Then, 10 $\mu \mathrm{l}$ of the MPESD solution was deposited on a carbon-coated copper grid and negatively stained with $10 \mu \mathrm{l}$ of $2 \% \mathrm{w} / \mathrm{v}$ uranyl acetate. Excess solvent was removed with a Whatman No.1 filter paper and allowed to air-dry in a desiccator for further observation by a transmission electron microscope (TEM, Tecnai 12, Philips, OR, USA).

\section{Physical stability of MPESD on clays}

The stability of MPESD on clay was investigated by mixing MPESD with various types of clay; mica, $\mathrm{SiO}_{2}$, Talc, and $\mathrm{TiO}_{2}$, at a MPESD to clay mass ratio of 1:10 using mortar and pestle. The samples were stored at room temperature for $1 \mathrm{mo}$, and the physical appearance of the mixtures was visually observed.

\section{In vitro permeation studies of the mixture of MPESD and clay}

To evaluate the effects of clay on the $\alpha$-mangostin released from MPESD, in vitro permeation of the MPESD was studied using a vertical Franz diffusion cells (PermeGear, Hellertown, USA) maintained at $32 \pm 1^{\circ} \mathrm{C}$. The diffusion area was $2.46 \mathrm{~cm}^{2}$ with $12 \mathrm{ml}$ of receptor medium, DI water. The porcine ear epidermis was fitted between a donor and receptor. The subcutaneous fat tissue was removed from the full-thickness ear skin which had been excised from the porcine ear, obtained from the slaughterhouse. Then, the epidermis was carefully separated from the dermis, using a heat separation technique, after the skin had been immersed in hot water at $60 \pm 1^{\circ} \mathrm{C}$ for $2 \mathrm{~min}$. The transepidermal water loss (TEWL) value of the separated epidermis was determined using a Tewameter (Model TM 300, Courage and Khazaka electronic GmbH, Germany). A TEWL value of less than $15 \mathrm{~g} / \mathrm{m}^{2} \mathrm{~h}$ was used as an indicator of the undamaged epidermis. The study was carried out with the approval of the Naresuan University Animal Ethics Committee, Phitsanulok, Thailand (5802002).

After the skin equilibration for $30 \mathrm{~min}$, the mixture of MPESD and clay, at the mass ratio of $1: 10$, was evenly spread on the porcine epidermis. Then, $500 \mu \mathrm{l}$ of the receptor medium was taken at predetermined time intervals of 15, 30, 60, 120 and $240 \mathrm{~min}$ and immediately replaced by fresh receptor medium. The amount of $\alpha$-mangostin permeation was determined by a UV-Vis spectrophotometer (Genesys 10 Series, Thermo Fisher Scientific Inc., USA) at $320 \mathrm{~nm}$.

\section{Preparation of MPESD-based clay facial mask powders}

Based on the results from the in vitro permeation studies of the MPESD, mica, Talc and $\mathrm{SiO}_{2}$ were selected as clay-based facial mask powders. The clay-based phase was prepared by dissolving glycerin, propylene glycol, Tween 80 in the DI water before mixing with the mixture of mica, $\mathrm{SiO}_{2}$ and Talc using mortar and pestle. Then, MPESD (1:4:0.5) was gentle mixed with the clay-based phase to obtain the MPESD-based clay facial mask powders. The sample was kept in a desiccator at room temperature for $1 \mathrm{~d}$ to evaporate the DI water.

\section{Skin irritation test in healthy volunteers}

The safety of the MPESD-based clay facial mask was determined using a $4 \mathrm{~h}$ human patch test [9]. The clinical study protocol was approved by the Institutional Research Board, Naresuan University, Phitsanulok, Thailand (approval number 004/58, 27 May 2016). Volunteers were enrolled using the inclusion criteria: (i) Healthy Thais, either gender, aged 20-50 yeras; (ii) no history of smoking, alcohol or drug use; or allergies to cosmetics within the past 3 mo. Participants were excluded if they (i) have been to exposed to a topical steroid, alpha hydroxy acids (AHAs) or salicylic acid within the past 3 mo before the study; (ii) received treatment with a topical medicine within 1 mo before the study; (iii) had a skin disease, or wound on inner forearm; (iv) history of atopic dermatitis or skin hypersensitivity reaction. Written informed consent was obtained from 30 participating volunteers.

The design of this study was a randomized, double-blind controlled trial, with study samples coded and randomized at the source, and with the volunteers, investigators and independent statistician blind to the coding until after study and initial data analysis had completed. The tested product was MPESD-based clay facial mask containing $\alpha$-mangostin $\sim 0.03 \mathrm{mg} / \mathrm{ml}$ whereas $10 \%(\mathrm{w} / \mathrm{v}) \mathrm{SLS}$ aqueous solution was used as a positive control. The baseline measurement was performed in a room maintained at $25 \pm 2{ }^{\circ} \mathrm{C}$ and $50 \pm 5 \%$ relative humidity after a 30 min rest for equilibration. A Webril pad, $1.5 \times 1.5 \mathrm{~cm}^{2}$ containing $0.2 \mathrm{ml}$ of sample, was then randomly applied to the volunteer inner forearm for $4 \mathrm{~h}$. Treatment sites were evaluated for the presence of irritation using a 2 point scale at 0.5 and $24 \mathrm{~h}$ after removal of the patch. Erythema, scaling, and fissuring of the skin were assessed by the dermatologist using the Frosch and Klingman scale. In addition, skin irritation was identified by transepidermal water loss (TEWL) using Tewameter $₫$ [Tewameter ${ }^{\circledR}$ TM 210 Courage and Kazaka, Cologne, Germany).

\section{Statistical analysis}

The results were expressed as mean \pm standard deviation (SD). Differences between the groups were compared by one-way ANOVA 
followed by Tukey's post hoc test. The results were considered to be statistically significant at ${ }^{*} \mathrm{P}<0.05$. Paired t-test was used to determine the difference in mean outcomes between tested and positive control sides, at 0.5 and $24 \mathrm{~h}$. The level of statistical significance was set at 0.05 .

\section{RESULTS AND DISCUSSION}

\section{Preparation of MPE and $\alpha$-mangostin content analysis}

Preparation of MPE using the method described above produced the powder extract with the yield of $24.05 \%(\mathrm{w} / \mathrm{w})$ compared to the dried powder weight. The appearance of the MPE was a brown solid powder. Based on HPLC analysis, $\alpha$-mangostin was found as the major compound in MPE with $29.44 \pm 0.32 \%(w / w)$.

\section{Preparation of the mangosteen peel extract solid dispersion (MPESD)}

MPESD was successfully prepared using the melting-solvent method. By dissolving MPE in a minimum volume of the absolute ethanol before mixing with the molten aqueous PVP K30 without and with poloxamer 188 , the homogeneous mixture was obtained when heated at $\sim 60^{\circ} \mathrm{C}$. This due to the water can act as a plasticizer and further reduce the glass transition temperature (Tg) of PVP K30 to below $50^{\circ} \mathrm{C}[10]$. Therefore, the MPE could be dissolved easily and completely in PVP K30, without and with poloxamer 188. After rapid cooling, the composition solidified and then the molecular dispersion of the MPE in PVP K30 matrix was achieved. After drying and grinding, the obtained MPESD powders were found to be fine and orange-yellowish powders.

\section{Percentage of drug recovery and drug loading}

All MPESD preparations showed high $\alpha$-mangostin recovery efficiency, $\sim 100 \%$, indicating that the amount of PVP K30 and poloxamer 188 have no effect on the drug recovery efficiency. In addition, MPESD showed similar drug loading, and recovery efficiency as compared to those of physical mixing, table 1 . This suggested that $\alpha$-mangostin was not degraded during the preparation process by melting-solvent method.

Table 1: The effects of PVP K30 and poloxamer 188 content on the percentage of $\alpha$-mangostin recovery and $\alpha$-mangostin loading from MPESD

\begin{tabular}{|c|c|c|c|c|}
\hline \multirow[t]{2}{*}{ Mass ratio of MPE: PVP K30: poloxamer 188} & \multicolumn{2}{|c|}{$\alpha$-mangostin recovery $(\%) \pm S D$} & \multicolumn{2}{|c|}{$\alpha$-mangostin loading (\%)土SD } \\
\hline & MPESD & MPEPM & MPESD & MPEPM \\
\hline $1: 2$ & $103.49 \pm 2.74$ & $96.75 \pm 7.38$ & $11.64 \pm 0.31$ & $10.69 \pm 0.82$ \\
\hline $1: 4$ & $102.68 \pm 0.51$ & $103.79 \pm 5.92$ & $6.72 \pm 0.03$ & $6.54 \pm 0.37$ \\
\hline $1: 2: 0.25$ & $100.55 \pm 2.39$ & $97.26 \pm 2.38$ & $12.17 \pm 0.29$ & $9.53 \pm 0.23$ \\
\hline $1: 2: 0.5$ & $102.40 \pm 1.92$ & $98.40 \pm 4.83$ & $11.55 \pm 0.22$ & $8.93 \pm 0.44$ \\
\hline $1: 2: 0.75$ & $101.79 \pm 2.48$ & $97.19 \pm 2.44$ & $7.98 \pm 0.19$ & $8.25 \pm 0.21$ \\
\hline $1: 4: 0.25$ & $100.13 \pm 3.79$ & $99.39 \pm 3.21$ & $5.90 \pm 0.22$ & $5.90 \pm 0.19$ \\
\hline $1: 4: 0.5$ & $103.65 \pm 4.35$ & $96.77 \pm 3.38$ & $5.50 \pm 0.23$ & $5.48 \pm 0.19$ \\
\hline $1: 4: 0.75$ & $96.27 \pm 4.76$ & $96.49 \pm 1.90$ & $5.10 \pm 0.25$ & $5.09 \pm 0.10$ \\
\hline
\end{tabular}

The results are presented as mean \pm standard deviation; $\mathrm{n}=3$.

\section{Solubility study}

The effects of PVP K30 and poloxamer 188 content on the $\alpha$ mangostin water solubility were investigated. MPESD illustrated a mark improvement in the dissolution behavior over the MPEPM and MPE. The $\alpha$-mangostin water solubility of MPE was found to be $10.62 \pm 0.27 \mu \mathrm{g} / \mathrm{ml}$, which at least 50 times lower than that of the MPESD (1:2) prepared with PVP K30 as a carrier, $\sim 0.5 \mathrm{mg} / \mathrm{ml}$, table 2. The $\alpha$-mangostin water solubility of MPESD increased as the amount of PVP K30 and poloxamer 188 increased (ANOVA analysis, $\mathrm{P}<0.05)$. MPESD (1:4) showed higher $\alpha$-mangostin water solubility than MPESD (1:2), $\sim 0.8$ and $0.5 \mathrm{mg} / \mathrm{ml}$, respectively. Nevertheless, MPESD with poloxamer 188 as a co-carrier, MPESD (1:4:0.25), showed a substantial improvement in $\alpha$-mangostin water solubility of $\sim 6.5 \mathrm{mg} / \mathrm{ml}$. The water solubility was further enhanced by increasing poloxamer 188 content, MPESD (1:4:0.5) showed water solubility of $\sim 7.7 \mathrm{mg} / \mathrm{ml}$. However, the $\alpha$-mangostin water solubility of MPESD prepared with the mass ratio of 1:4:0.5 and 1:4:0.75 showed no significant difference (ANOVA analysis, $\mathrm{P}>0.05$ ).

The improved dissolution behavior of MPESD with PVP K30 would be a result from the molecular dispersion of $\alpha$-mangostin in carriers and hydrophilic property of PVP K30 $[11,12]$. In addition, as shown in table 2, the presence of poloxamer 188 could significantly improve the $\alpha$-mangostin water solubility up to 727 times higher than MPE. This could be attributed to its high HLB value of 22 and surfactant property of poloxamer $[13,14]$.

The physical mixtures also exhibited higher $\alpha$-mangostin water solubility than MPE. This could be explained by the hydrophilicity of polymer increases wettability and dispersibility of drug in the medium, and thus, reducing interfacial tension between the hydrophobic drug and the aqueous medium [15]. Nevertheless, MPEPM showed lesser $\alpha$-mangostin water solubility than MPESD confirming no interaction between $\alpha$-mangostin and carriers.

Table 2: The effects of PVP K30 and poloxamer 188 content on the $\alpha$-mangostin water solubility of the MPESD

\begin{tabular}{lll}
\hline Mass ratio of MPE: PVP K30: poloxamer 188 & \multicolumn{1}{c}{$\boldsymbol{\alpha - m a n g o s t i n ~ w a t e r ~ s o l u b i l i t y ~ ( m g / m l ) ~} \mathbf{l}$ MD } \\
\cline { 2 - 3 } & MPESD & $0.12 \pm 0.03$ \\
\hline $1: 2$ & $0.51 \pm 0.05$ & $0.13 \pm 0.01$ \\
$1: 4$ & $0.82 \pm 0.03$ & $0.23 \pm 0.02$ \\
$1: 2: 0.25$ & $1.38 \pm 0.01$ & $0.28 \pm 0.13$ \\
$1: 2: 0.5$ & $2.03 \pm 0.23$ & $0.42 \pm 0.10$ \\
$1: 2: 0.75$ & $4.72 \pm 0.24$ & $0.28 \pm 0.01$ \\
$1: 4: 0.25$ & $6.55 \pm 0.50$ & $0.34 \pm 0.01$ \\
$1: 4: 0.5$ & $7.72 \pm 0.46$ & $0.71 \pm 0.16$ \\
\hline
\end{tabular}

The results are presented as mean \pm standard deviation; $\mathrm{n}=3$.

\section{Physico-chemical characterization of the MPESD}

The dynamic light scattering (DLS) analysis showed that the amount of poloxamer 188 was a critical parameter for controlling the particle size.
Upon dissolved in water, the MPESD prepared using only PVP K30 as a carrier showed a particle size of $\sim 200 \mathrm{~nm}$, larger than those prepared with poloxamer 188 as a co-carrier, $120-170 \mathrm{~nm}$, table 3 . The results revealed that the mean particle size of MPESD tended to decrease as the 
poloxamer188 content was increased. Poloxamer 188, as a surfactant, can reduce the interfacial energy on the surface of MPESD leading to a decrease in the particle size. In addition, all formulations possessed a polydispersity index of 0.17-0.30 indicating a narrow size distribution.

Table 3: The effects of PVP K30 and poloxamer 188 content on the mean particle size (MS) and polydispersity index (PI) of the MPESD

\begin{tabular}{lll}
\hline Mass ratio of MPE: PVP K30: poloxamer 188 & MPESD & MS (nm) $\mathbf{1}$ SD \\
\hline $1: 2$ & $191.4 \pm 7.9$ \\
$1: 4$ & $189.9 \pm 12.5$ \\
$1: 2: 0.25$ & $168.5 \pm 3.1$ \\
$1: 2: 0.5$ & $153.7 \pm 4.9$ \\
$1: 2: 0.75$ & $148.0 \pm 4.5$ \\
$1: 4: 0.25$ & $141.7 \pm 6.1$ \\
$1: 4: 0.5$ & $114.2 \pm 1.2$ \\
$1: 4: 0.75$ & $118.5 \pm 5.8$ \\
\hline
\end{tabular}

The results are presented as mean \pm standard deviation; $\mathrm{n}=3$.

Upon dilution with water, the TEM micrograph of the MPESD at the mass ratio of 1:4:0.5 showed spherical micelles with a mean particle size of $\sim 120 \mathrm{~nm}$, fig. 1 . The forming micelles were composed of the MPE enclosed by PVP K30 and poloxamer 188. Thus, the MPESD has been demonstrated to improve the water solubility of $\alpha$-mangostin.

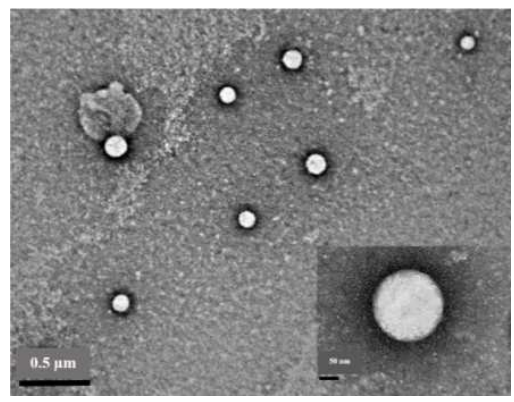

Fig. 1: TEM micrograph of MPESD prepared with the MPE to PVP $K 30$ to poloxamer 188 mass ratio of $1: 4: 0.5$. At a mangnificant of 18,500

\section{Physical stability of the MPESD on clays}

Before developing the MPESD-based clay facial mask powders, the physical stability of the MPESD with various types of clay mixtures was visually observed after 1 mo storage at the room temperature. All MPESD formulations showed good physical appearance when mixed with tested clays. The mixtures were dry powders similar to those before mixing. Therefore, the MPESD at the mass ratio of 1:4:0.5 was selected for preparing the MPESD-based clay facial mask powders due to its high $\alpha$-mangostin water solubility.

\section{In vitro permeation studies of the mixture of MPESD and clay}

In vitro permeation study using porcine ear epidermis was performed to confirm the $\alpha$-mangostin adsorption capacity of clays. As expected, MPE showed no $\alpha$-mangostin permeation through the porcine ear epidermis due to its low water solubility. On the contrary, the MPESD showed a fast permeation characteristic with the high $\alpha$-mangostin permeation of $\sim 60 \%$ at $15 \mathrm{~min}$, fig. 2 . The MPESD significantly increased the $\alpha$-mangostin water solubility. As a result, there is a high concentration gradient of the $\alpha$-mangostin at the interface, which is the driving force for the $\alpha$-mangostin permeation. The mixture of MPESD: mica and MPESD: Talc exhibited similar permeation profile as the MPESD solution suggesting less $\alpha$ mangostin adsorption on mica and Talc. In contrast, the mixture of MPESD: $\mathrm{SiO}_{2}$ and MPESD: $\mathrm{TiO}_{2}$ showed the lower $\alpha$-mangostin permeation. MPESD: $\mathrm{SiO}_{2}$ and MPESD: $\mathrm{TiO}_{2}$ exhibited $\alpha$-mangostin permeation of $\sim 30 \%$ within 15 min. Thus, these results strongly confirm that types of clays play an important role for active ingredient adsorption. Moreover, MPESD could be used as a mean to significantly improve the $\alpha$-mangostin permeation that could be a benefit for facial mask application.

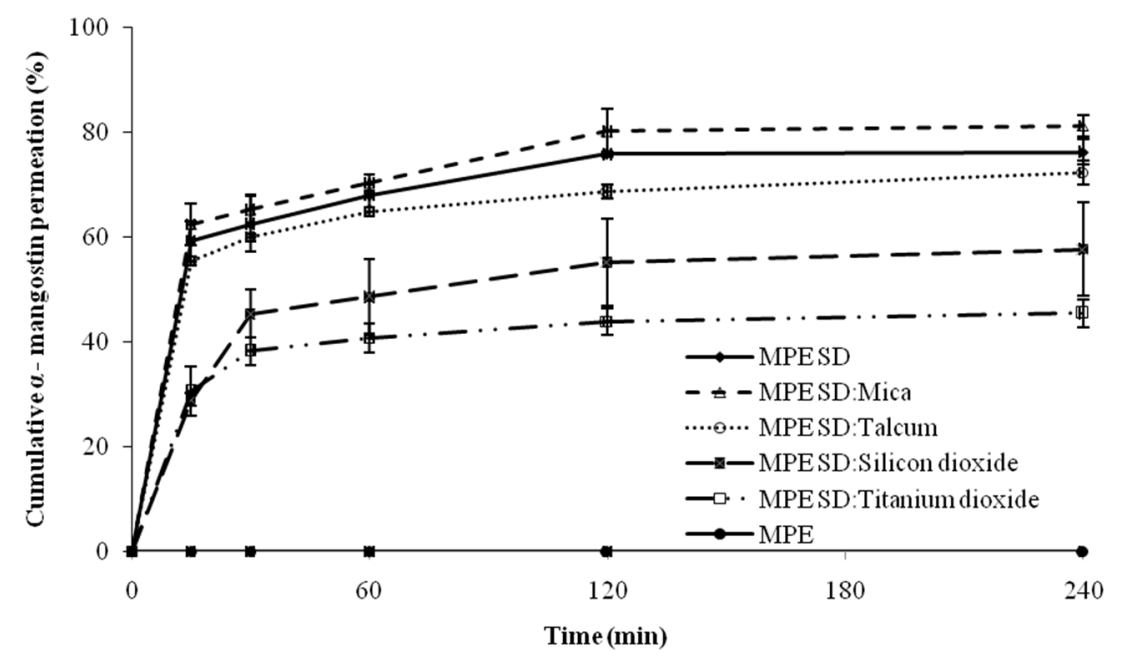

Fig. 2: In vitro permeation profiles of MPE, MPESD and MPESD incubated with different clays, mica, silicon dioxide, talcum, and titanium dioxide, at a mass ratio of 1:10. MPESD prepared with the MPE to PVP K30 to poloxamer 188 mass ratio of 1:4:0.5. Error bars show 


\section{Evaluation of skin irritation in healthy volunteers}

Eleven male and 19 female volunteers were recruited, with a mean age of $29.40 \pm 6.90 \mathrm{y}$. None of the volunteers developed adverse events after the $4 \mathrm{~h}$ patch test. The main function of skin stratum corneum is to serve as a barrier by protecting skin from irritant permeation and preventing trans-epidermal water loss. Thus, an increased TEWL value, obtained by measuring water vapor loss from the skin, is considered a sensitive indicator of skin disruption [16]. SLS, an anionic surfactant, is commonly used as a positive control in the cytotoxicity assay. This due to SLS causing skin damage or destruction of the skin barrier leading to skin dryness. SLS might also penetrate and damage the deeper nucleated layers of the epidermis [17].
Treatment with the formulation for $4 \mathrm{~h}$ showed a continuing low TEWL similar to baseline indicating the absence of any skin disruption at both 0.5 and $24 \mathrm{~h}$ after patch removal, table 4 . In contrast, sites treated with $10 \%$ SLS showed persistency raised TEWLs than baseline at both times points tested indicating persistently damaged skin. The mean difference of TEWL values in MPESD-based clay facial mask was statistically significantly different compared to the positive control (10\% SLS) at 0.5 and $24 \mathrm{~h}$ indicating the skin responded to the challenge. This study confirmed that higher TEWL was associated with irritant exposure, TEWL indirectly assesses irritation through modification of the skin barrier.

Table 4: Skin irritation parameter of MPESD-based clay facial mask powder

\begin{tabular}{|c|c|c|c|c|c|c|c|}
\hline \multirow[t]{2}{*}{ Characteristics } & \multicolumn{3}{|c|}{ MPESD-based clay facial mask powders treatment \pm SD } & \multicolumn{3}{|c|}{ Positive control; $10 \%$ SLS \pm SD } & \multirow[t]{2}{*}{ P-value } \\
\hline & Baseline (B) & After (A) & A-B & Baseline (B) & After (A) & A-B & \\
\hline \multicolumn{8}{|c|}{ TEWL value $\left(\mathrm{g} \mathrm{h}^{-1} \mathrm{~m}^{-2}\right)$} \\
\hline $0.5 \mathrm{~h}$ & $9.30 \pm 2.49$ & $10.76 \pm 2.98$ & $1.45 \pm 2.53$ & $9.13 \pm 1.92$ & $15.19 \pm 4.14$ & $6.06 \pm 3.50$ & $>0.0005^{*}$ \\
\hline $24 \mathrm{~h}$ & & $9.73 \pm 2.20$ & $0.43 \pm 2.45$ & & $15.94 \pm 5.76$ & $6.81 \pm 5.28$ & $>0.0005^{* *}$ \\
\hline \multicolumn{8}{|c|}{ Visual scoring by a dermatologist } \\
\hline Erythema & $\mathrm{A}-\mathrm{B}$ & & & Baseline (B) & $A-B$ & & P-value \\
\hline $0.5 \mathrm{~h}$ & $0^{*}$ & & & $0.00 \pm 0.00$ & $0.13 \pm 0.22$ & & $>0.0005^{*}$ \\
\hline $24 \mathrm{~h}$ & & & & & $0.10 \pm 0.21$ & & $>0.0005^{* *}$ \\
\hline Dryness & A-B & & & Baseline (B) & $A-B$ & & P-value \\
\hline $0.5 \mathrm{~h}$ & $0^{*}$ & & & $0.00 \pm 0.00$ & $0.43 \pm 0.17$ & & $>0.0005^{*}$ \\
\hline $24 \mathrm{~h}$ & & & & & $0.47 \pm 0.13$ & & $>0.0005^{* *}$ \\
\hline Fissures & A-B & & & & & & \\
\hline $0.5 \mathrm{~h}$ & $0^{*}$ & & & & & & \\
\hline $24 \mathrm{~h}$ & & & & & & & \\
\hline
\end{tabular}

$0 *=$ no irritation identified by dermatologist, ${ }^{*}$ Statistical significance $(\mathrm{P}<0.05)$ between baseline and $0.5 \mathrm{~h},{ }^{* *}$ Statistical significance $(\mathrm{P}<0.05)$ between baseline and $24 \mathrm{~h}$, aErythema: $0=$ no evidence of erythema, $0.5=$ minimal or doubtful erythema, $1+=$ slight redness, spotty and diffuse, $2+=$ moderate and uniform redness, $3+=$ strong uniform redness, $4+=$ fiery redness, bryness: $0=$ no evidence of scaling, $0.5=$ dry without scaling or appears smooth and taut, $1+=$ fine or mild scaling, $2+=$ moderate scaling, $3+=$ severe scaling with large flakes, cFissures: $0=$ no evidence of fissures, $1+=$ cracks, $2+=$ single or multiple broader fissures, $3+=$ wide cracks with hemorrhage or weeping

These results were in agreement with a visual assessment by the dermatologist who detected no sign of skin irritation with the test clay, whereas $10 \%$ SLS showed erythema and dryness in all participants. No fissure was observed in both MPESD-based clay facial mask and the positive control, fig. 3. Therefore, the developed MPESD-based clay facial mask could be considered as mildness and safe for topical application.
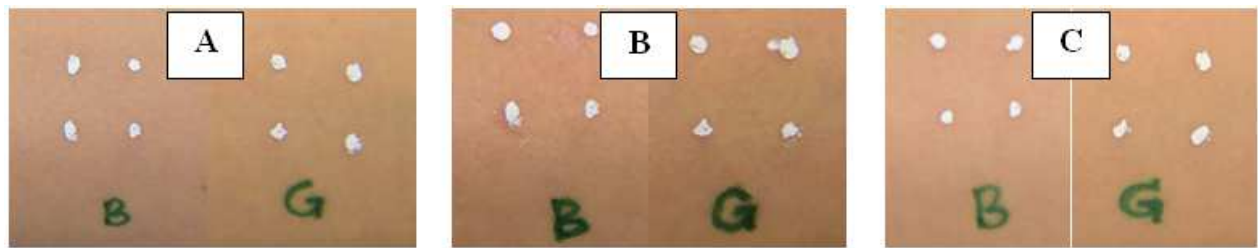

Fig. 3: Representative Photographs of inner forearm assessment at A) baseline, before patch application, B) $0.5 \mathrm{~h}$ after removing patch and $\mathrm{C}$ ) $24 \mathrm{~h}$ after removing patch. The area (B) was treated with positive control and area (G) was treated with MPESD-based clay facial mask

\section{CONCLUSION}

Solid dispersion (SD) is a powerful technique for increasing water solubility of poorly soluble substances. MPESD was successfully developed to improve water solubility of $\alpha$-mangostin. Compared to MPE, this technique showed greater $\alpha$-mangostin solubility and permeation. In addition, this study clearly showed that clays play a vital role in the permeation of the active substance through the skin. The selection of clays used in facial mask formulation is a critical step in the MPESD-based facial mask powders formulation. Thus, by selecting the proper clay base, the bioavailability of active substances in clay-based facial mask could be improved. In conclusion, MPESD demonstrates a promising technique for improving water solubility and permeation of $\alpha$-mangostin. In addition, it is safe for topical application and cosmetically acceptable. Nevertheless, double-blind, placebo-controlled trials in the individual should be performed in the efficacy study in the future to assure its cosmetic benefits.

\section{ACKNOWLEDGMENT}

This study was financially supported by the Agricultural Research Development Agency, Thailand (Grant numbers; R2256A025) and the Center of Excellence for Innovation in Chemistry (PERCH-CIC), Commission on Higher Education and Ministry of Education, Thailand. We are grateful to Udomsak Tangchaisuriya, MD, Faculty of Medical Sciences, Naresuan University for clinical evaluation. Many thanks to Mr. Roy Morien of the Naresuan University, Language Centre, for his editing assistance and advice on English expression in this document.

\section{AUTHORS CONTRIBUTIONS}

All authors have contributed equally to the study

\section{CONFLICT OF INTERESTS}

The authors declare no conflict of interest 


\section{REFERENCES}

1. Bergaya F, Theng BKG, Lagaly G. editors. Handbook of Clay Science. Amsterdam: Elsevier; 2006.

2. Pothitirat W, Chomnawang MT, Supabphol R, Gritsanapan W. Comparison of bioactive compounds content, free radical scavenging and anti-acne inducing bacteria activities of extracts from the mangosteen fruit rind at two stages of maturity. Fitoterapia 2009;80:442-7.

3. Marquez Valadez B, Lugo Huitron R, Valdivia Cerda V, Miranda Ramirez LR, Perez De La Cruz V, Gonzalez Cuahutencos 0 , et al. The natural xanthone $\alpha$-mangostin reduces oxidative damage in rat brain tissue. Nutr Neurosci 2009;12:35-42.

4. Ngawhirunpat T, Opanasopi P, Sukma M, Sittisombut C, Kat A, Adachi I. Antioxidant, free radical-scavenging activity and cytotoxicity of different solvent extracts and their phenolic constituents from the fruit hull of mangosteen (Garcinia mangostana). Pharm Biol 2010;48:55-62.

5. Pedraza Chaverri J, Cardenas Rodriguez N, Orozco Ibarra M, Perez Rojas JM. Medicinal properties of mangosteen (Garcinia mangostana). Food Chem Toxicol 2008;46:3227-39.

6. Aisha AFA, Ismail Z, Abu-salah KM, Majid AMSA. Solid dispersions of $\alpha$-mangostin improve its aqueous solubility through selfassembly of nanomicelles. J Pharm Sci 2012;101:815-25.

7. Vo CLN, Park C, Lee BJ. Current trends and future perspectives of solid dispersions containing poorly water-soluble drugs. Eur J Pharm Biopharm 2013;85:799-813.

8. Jessie Sofia Pamudji SW, Meisa Handini Tampara. Improvement of gliclazide's dissolution rate by using surface solid dispersion with avicel PH 101. Int J Pharm Pharm Sci 2014;6:461-5.
9. Basketter DA, York M, McFadden JP, Robinson MK. Determination of skin irritation potential in the human 4-h patch test. Contact Derm 2004;51:1-4.

10. Fitzpatrick S, McCabe JF, Petts CR, Booth SW. Effect of moisture on polyvinylpyrrolidone in accelerated stability testing. Int J Pharm 2002;246:143-51.

11. Lu $\mathrm{Y}$, Tang $\mathrm{N}$, Lian $\mathrm{R}, \mathrm{Qi} \mathrm{J}, \mathrm{Wu} \mathrm{W}$. Understanding the relationship between wettability and dissolution of solid dispersion. Int J Pharm 2014;465:25-31.

12. Salman A, Nasrul E, Rrival H, Ben ES, Zaini E. Physicochemical characterization of amorphous solid dispersion of ketoprofenpolyvinylpyrrolidone K-30. Int J Pharm Pharm Sci 2015;7:20912.

13. Chisti Y. Poloxamers and poloxamines in nanoparticle engineering and experimental medicine. Trends Biotechnol 2000;18:412-20.

14. Maraie NK, Alhamdany AT, Radhi AA. Efficacy of combination of solid dispersion technology on dissolution performance of nalidixic acid and cefdinir. Asian J Pharm Clin Res 2017;10:394401.

15. Vyas V, Sancheti P, Karekar P, Shah M, Pore Y. Physicochemical characterization of solid dispersion systems of tadalafil with poloxamer 407. Acta Pharm 2009;59:453-61.

16. Agner T. Basal transepidermal water loss, skin thickness, skin blood flow and skin colour in relation to sodium-lauryl-sulfateinduced irritation in the normal skin. Contact Derm 1991; 25:108-14.

17. Fartasch M, Schnetz E, Diepgen TL. Characterization of detergent-induced barrier alterations-effect of barrier cream on irritation. J Investig Dermatol Symp Proc 1998;3:121-7. 